\title{
The Relationship between Spirituality and Job Satisfaction
}

\author{
Hojjat Taheri Goodarzi(1) , Mostafa Kaviani(2) \\ 1. Department of Public Management, Borujerd Branch, ISLAMIC AZAD UNIVERSITY,BORUJERD,IRAN \\ (Corresponding Author) \\ 2.Master of Public Management, Borujerd Branch, ISLAMIC AZAD UNIVERSITY,BORUJERD, IRAN
}

\begin{abstract}
This study have been conduction to consider the relation of spirituality and job satisfaction of pipe and telecommunication company' personnel of Lorestan region. Spirituality have been considered as a variable with significant and purposeful working, humanism, honesty and sacrifice and life sanctification as method of correlation type, at statistical society $(N=218)$ by using Morgan sampling table $(n=140)$. To collecting the data we have also organizational spirituality and job satisfaction with final coefficient \% 736 and $\% 769$ and \% 843 resections base on Cronbach Alpha.

The collected data have been analyzed by SPSS statistical soft ware and Pierson correlation test and other devices at descriptive and deductive static matter. We can conclude base on analyzing the finding of the study that spirituality and job satisfaction of the personnel have a significant statistical relation and are the basic indexes on job satisfaction variable. Results show the importance of this relation which is invisible in sense of relation of mentioned variables and it show that we must pay attention to that more than ever at the organizations.
\end{abstract}

Keywords: Spirituality, Subjective Spirituality, Organizational Spirituality, Job Satisfaction

\section{Introduction:}

We now live in the era which named intricacy and changing era. The organizations in this era are in order and disorder mood and between two paradox mood constantly. Management theorists have contributed many theories to run these situations such as: Holographic organizations, Entrepreneurial organizations and chaos theory . spirituality at the organizations is a new phenomenon which has attracted the attentions of many organization and management theorists and also managers at different levels. Base of this many of them have defined spirituality as a constant source which can help them at collision and confusion periods solve the order and disordering paradox problem at different stages[14] . Management at the organizations not only at theory point of view but also at functional point of view, has been recently the subject of a powerful force named spirituality which if conducted truly, it seemed that it does have the necessary capacity to convert that to the most deepest collaboration not only at professional bases but also to show the real humanism.[7].

Today managers have more intended to compilation the spirituality and management . This compilation, does have the deepest values which affect on their jobs and also is the promising of the more success. The managers due to co-interests obligate themselves to spirituality [19].

This power full forces do affected on management and commercial principals and its theories such that is considered as a change and basic improvement at commerce and management field at theorists point of view.[18]

Some of the organization and management researchers believe that spirituality at the organization, does have a direct relation at personnel jobs at doing the important purposes of subjective and organizational. These researchers believe that satisfying the most important requirement s of personnel can be investigated at the model of spirituality[10].

Modern paradigm basically have study the lawful, political and economic bases and consider the life internal aspects as the private affairs which every one must pay attention to that base on his / her own style. In other words : modern paradigm, which is improved to all over the world and accepts the human welfare responsibility, desolate a vast amount of human sensitivity and provide a condition in which human and specially the western men do have a sense of dissatisfaction and uneasiness . it cause they tend to spirituality, religious and religious customs to remove the spirituality vacuum [16]. Appearing concepts like ethic, reality, believing the God or a superior force, honesty , moral sense, scarifying, trust, forgiveness, kindness, emotions , consideration, finding the meaning at the work, correlation to co- workers , persuasion of the co-workers , peace and harmony sense, humanism ,....to the studies and managerial actions and working all show that a new studies and managerial actions and working all show that a new paradigm is coming to be exist. Some of the researchers believe that this new paradigm which refer to Quantum Physics, Cybernetics Sciences and confusion theory, recognizing Sciences, religions and western and eastern customs, in fact is a reaction to rigid paradigm and is a modern mechanism and it is spirituality paradigm [11]. 
Job satisfaction is the general attitude of the person to his /her job and it is one of the factor which is effective in satisfaction and it's big effect in the individual and communicative personnel's life, researchers had been focus on this matter for more than half century and they want to find that which factors relate to personnel job satisfaction [4].

\section{Statement of the problem:}

The concept of job satisfaction has many times studied and different definitions also has been provided , but certainly different definitions is related to different researcher's attitude and valuable factors. New can also realize that valuable concepts is related to job satisfaction significantly then we conclude the one who does have a positive attitude to his / her job will has job - satisfaction too and vice versa[15].

While the job -environment is known as a philosophic and individual structure, almost all the scientific definitions, has defines spirituality as an abstract concept with deep values at the job environment. This definition is related to the attempts to find the final object of the person in making a strong relation to his / her co - workers and other men at the work environment .

Further more it make a kind of balance and symphony between person's inner believes and organization values. Base on that spirituality is defined at work environment as a recognition which the personal realize that they find they have an inner life.

That they can improve that via significant working in the work environment and at the society too. To some of people, spirituality at their working is a kind of religious connection, while it doesn't mean that to other people. In fact traditional most of the spirituality interests are refer to religion. But today to most of the men spirituality doesn't relate to a certain religion, but it's base is the individual values and philosophy .

Values, attitudes, aims and meaning of the life and self-believing,... are all the spirituality indexes , then to find a better definition of personnel spirituality dimensions [14]. Although physical and psychological dimensions has country which findings show the relation between spirituality and job satisfaction.

Researchers believe that if we want the humanism resources strategies to be effective, we must study the humanism resources strategies to be effective, we must the people at various aspects.

Then considering the government's attention bat using the purposeful and self - believed and state services management rules.

This matter make researchers to study the personnel's job satisfaction's criterion at a scientific research process and related to the topics such as individual and organizational spirituality and this study realize the spiritual personnel's lacks and provide some solutions. Then this question may be come to our minds : what is the relation of spirituality and job satisfaction?

\section{The importance and necessity of researching:}

The new attitude of working at 21 th century is focusing on personnel's spirituality at job environment .the basic question related to the importance of spirituality is that why there is an increasing interest to this matter?

The answer is that the society has improved in terms of leisure time, sciences and opposite views , then people tend to have spirituality not only at their works but also at other life levels. Other answer is the interest that interest can be improved from the individual creativeness to be warranty to organization purposes [2] . At 21th Century state and private organizations will have a big contest to receive success's indexes at their aims, because organizations besides the environmental stimulations such as being universally must continue their works . this problem simultaneously at personnel's emotions cause disappointing, fear, uncertainty and operation's education, then at this situation, the upper level of personnel's needs will be obvious which is the necessity to spirituality and by a spirituality philosophy, duty attitude and main values and also conduction, these value will cause, results such as increasing and improving the operation, organizational warranty, improving the ethics and being successful at working and organization.

Gradually these factors cause other organizational results namely job satisfaction, spirituality cause a final property and finally they will be satisfied at their lives . $\mathrm{v}$ at job will proud a meaning to the job life and cause the person does have a positive attitude to his job and consider his / her work as a high and excelsior aim. The main result of spirituality at work is peace, happiness and hope which are the fundamental factors of inner satisfaction. This significant satisfaction, is both satisfaction at individual life and job satisfaction at working life [13]. instances:

To justify the investigation about spirituality, beside the mentioned reasons, we can refer to these

By spirituality at organizations a harmonic view to organization, family and the society will be provided to the personnel . most of the personnel do have a separated work life, family life and spiritual life .In terms of social 50 to $70 \mathrm{~h}$ working a week, doing the praying, and the rest to the family is the fundamental of this separation [9]. 
Today it seems that the personnel investigate some things more and higher than material compensations every where they work. They want a significant, hop fullness job and balance their lives.

Organizations work with improved personnel who want to find a significant and purpose full job. Spirituality at job is the definition of the personnel whose jobs are significant, purposeful and satisfying . spirituality is connected to improving the creativeness, honesty, relying and warranty at job and also is related to improving the individual evolution of the personnel.[5].

\section{Study object:}

The main object:

Studying the relation of spirituality and job satisfaction of pipe and telecommunication company's personnel of Lorestan region.

\section{Secondary objects:}

1. Studying job - satisfaction of pipe and telecommunication company 's personnel of Lorestan region.

2. Studying spirituality at pipe and telecommunication company 's personnel of Lorestan region.

3. Studying the relation between individual spirituality and job satisfaction of and telecommunication company 's personnel of Lorestan region.

4. Studying the relation between organizational spirituality and job satisfaction of pipe and telecommunication company's personnel of Lorestan region.

5. Studying the relation between individual spirituality and organizational spirituality of pipe and telecommunication company 's personnel of Lorestan region.

\section{Research Questions:}

The main Question:

Is there any relation between spirituality and job satisfaction of pipe and telecommunication company 's personnel of Lorestan region?

\section{Secondary questions:}

1. Is there any relation between individual spirituality and job satisfaction of pipe and telecommunication company 's personnel of Lorestan region?

2. Is there any relation between organizational spirituality and job satisfaction of pipe and telecommunication company 's personnel of Lorestan region?

3. Is there any relation between individual spirituality and organizational spirituality of pipe of pipe and telecommunication company's personnel of Lorestan region?

\section{Research Methodology:}

This study is functional in of its aim and terms of method is descriptive and its type is correlation and to analyzing the collected data Pierson coefficient has been used [17].

The statistical society of this study is composed of 218 person of pipe and telecommunication company 's personnel of Lorestan region which by Morgan table the sample is determined as a group of 140 Pierson.

We have used three standard questionnaires named individual spirituality standard (wheat) and organizational spirituality (kolodinsky) and job satisfaction (Minnesota job satisfaction questionnaire) with final coefficient of $\% 736, \% 769$ and \%843 respectively base on Cronbach Alpha to investigate personnel's individual spirituality and organizational spirituality and job satisfaction. The collected data has been analyzed by SPSS which is a statistical software and by Pierson coefficient test and other devices at descriptive and deductive field[6].

\section{Analyzing the data:}

Question 1 - Is there any relation between age and job satisfaction?

Table 1: Pierson test to answer the first study question from this table we can see there is not any relation between age and job satisfaction base on Pierson test.

\begin{tabular}{||c||c||c||}
\hline \hline Test amount & numbers & Level of significant \\
\hline \hline 0.083 & 140 & .333 \\
\hline \hline
\end{tabular}

Question 2 -Is there any relation between age and individual spirituality?

Table 2 : Pierson test to answer the second study question:

\begin{tabular}{||c||c||c||}
\hline \hline Test amount & numbers & Level of significant \\
\hline \hline-0.019 & 140 & 0.824 \\
\hline
\end{tabular}


From this table we can see there is not any relation between age and individual spirituality base on Pierson test .

Question 3- Is there any relation between age and organizational spirituality?

Table 3 : Pierson test to answer the third study question:

\begin{tabular}{||c||c||c||}
\hline \hline Test amount & numbers & Level of significant \\
\hline \hline-0.019 & 140 & 0.824 \\
\hline \hline
\end{tabular}

From this table we can see there is not any relation between age and organizational spirituality base on Pierson test .

Question 4- Is there any relation between record of service and job satisfaction?

Table 4: Pierson test to answer the fourth study question:

\begin{tabular}{|c|c|c|}
\hline Test amount & numbers & Level of significant \\
\hline 0.058 & 140 & 0.493 \\
\hline
\end{tabular}

From this table we can see there is not any relation between record of service and job satisfaction base on Pierson test.

Question 5- Is there any relation between record of service and individual spirituality?

Table 5 : Pierson test to answer the fifth study question:

\begin{tabular}{||c||c||c||}
\hline \hline Test amount & numbers & Level of significant \\
\hline \hline-0.015 & 140 & 0.585 \\
\hline \hline
\end{tabular}

From this table we can see there is not any relation between record of service and individual spirituality base on Pierson test.

Question 6- Is there any relation between record of service and organizational spirituality?

Table 6: Pierson test to answer the sixth study question:

\begin{tabular}{||c||c||c||}
\hline \hline Test amount & numbers & Level of significant \\
\hline \hline-0.047 & 140 & 0.584 \\
\hline
\end{tabular}

From this table we can see there is not any relation between record of service and organizational spirituality base on Pierson test.

Question 7- Is there any relation between education and job satisfaction?

Table 7:pierson test to answer the seventh study question:

\begin{tabular}{||c||c||c||}
\hline \hline Test amount & numbers & Level of significant \\
\hline \hline-0.025 & 140 & 0.765 \\
\hline
\end{tabular}

From this table we can see there is not any relation between education and job satisfaction base on Pierson test. Question 8- Is there any relation between education and individual spirituality ?

Table 8: Pierson test to answer the eighth study question:

From this table we can see there isn't any relation between education and individual spirituality base on Pierson test.

\begin{tabular}{||c||c||c||}
\hline \hline Test amount & numbers & Level of significant \\
\hline \hline-0.105 & 140 & 0.218 \\
\hline \hline
\end{tabular}

Question 9- Is there any relation between education and organizational spirituality?

Table 9: Pierson test to answer the ninth study question:

\begin{tabular}{||c||c||c||}
\hline \hline Test amount & numbers & Level of significant \\
\hline \hline .041 & 140 & 0.628 \\
\hline
\end{tabular}


From this table we can see there is not any relation between education and organizational spirituality base on Pierson test.

Question 10- Is there any relation between marriage and job satisfaction?

Table 10:pierson test to answer the ninth tenth question:

\begin{tabular}{||c||c||c||}
\hline \hline Test amount & numbers & Level of significant \\
\hline \hline 0.141 & 140 & 0.095 \\
\hline \hline
\end{tabular}

From this table we can see there is not any relation between marriage and job satisfaction base on Pierson test. Question 11- Is there any relation between marriage and individual spirituality?

Table 11: Pierson test to answer the ninth eleventh question:

\begin{tabular}{||c||c||c||}
\hline \hline Test amount & numbers & Level of significant \\
\hline \hline 0.141 & 140 & 0.095 \\
\hline
\end{tabular}

From this table we can see there isn't any relation between marriage and individual spirituality base on Pierson test.

Question 12- Is there any relation between marriage and organizational spirituality ?

Table 12: Pierson test to answer the ninth twelfth question:

\begin{tabular}{||c||c||c||}
\hline \hline Test amount & numbers & Level of significant \\
\hline \hline 0.101 & 140 & 0.234 \\
\hline \hline
\end{tabular}

From this table we can see there isn't any relation between marriage and organizational spirituality . Question 13- Is there any relation between personnel's and job satisfaction?

Table 13: Pierson test to answer the ninth thirteenth question:

\begin{tabular}{||c||c||c||c||}
\hline \hline number & average & Standard deviation & Standard error \\
\hline \hline 140 & 3.96 & 0.33 & 0.03 \\
\hline \hline
\end{tabular}

Table 14: T- test study to answer the thirteenth study question:

\begin{tabular}{||c||c||c|c||}
\hline \hline \multicolumn{3}{|c|}{ Test value $=3$} \\
\hline \hline T Amount & Free degree & Level of significant & Different average \\
\hline \hline 30.99 & 139 & 0.000 & 0.96 \\
\hline
\end{tabular}

Considering the significance of one way T-test at $\% 1$ level, it show that the average of job satisfaction with level of significance at 3 does have a satisfaction difference, then job satisfaction of the personnel is more than expectation.

Question 14- what is the extent of individual spirituality between the personnel?

Table 15: The description of the data at T-test student to answer the fourteenth study question:

\begin{tabular}{||c||c||c||c||}
\hline \hline number & Average & Standard deviation & Standard error \\
\hline \hline 140 & 4.21 & 0.33 & 0.028 \\
\hline
\end{tabular}

Table 16:T-test student to answer the fourteenth study question:

\begin{tabular}{|c|c|c|c|}
\hline & & & Test value $=3$ \\
\hline Different average & Free degree & "Different average & "Different average \\
\hline$\overline{42.73}$ & 139 & 0.000 & 1.21 \\
\hline
\end{tabular}

Considering the significance of one way $\mathrm{T}$ test at $\% 1$ level, it show that the average of individual spirituality with level of significance at 3 does have a satisfaction difference, then individual spirituality of the personnel is more than average or in other words the personnel do have a high individual spirituality. 
Question 15- what is the extent of organizational spirituality between the personnel?

Table 17: The description of the data at $\mathrm{T}$ test student to answer the fifteenth study question:

\begin{tabular}{|c|c|c|c|}
\hline number & Average & "Standard deviation & Standard error \\
\hline 140 & 3.17 & 0.36 & 0.030 \\
\hline
\end{tabular}

Table 18: T test student to answer the fifteenth study question:

\begin{tabular}{|c|c|c|c|}
\hline & & & Test value $=3$ \\
\hline Different average & Free degree & Different average & Different average \\
\hline 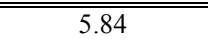 & 139 & 0.000 & 0.17 \\
\hline
\end{tabular}

Considering the significance of one way $\mathrm{T}$ test at $\% 1$ level, it show that the average of organizational spirituality with level of significance at 3 does have a satisfaction difference, then personnel's organizational spirituality is more than expectation.

Question 16- If the personnel job satisfaction Considering their service's region are different?

Table 19: ANOVA test to answer the sixteenth study question:

\begin{tabular}{|c|c|c|c|c|c|c|}
\hline \multicolumn{2}{|c|}{} & Total squares & Free degree & Squares average & F & Level of significant \\
\hline \multirow{2}{*}{} & $\begin{array}{c}\text { Between the } \\
\text { groun }\end{array}$ & 0.452 & 5 & 0.090 & 0.659 & 0.655 \\
\cline { 2 - 6 } & \begin{tabular}{c} 
In the group \\
\cline { 2 - 5 }
\end{tabular} & 18.38 & 134 & 0.137 & & \\
\cline { 2 - 5 } & Total & 18.83 & 139 & & & \\
\hline
\end{tabular}

Considering the Test of variance analyze we can conclude that the service's region have any effect on the job satisfaction between the personnel at different region isn't different.

Question 17- If the personnel job satisfaction Considering the region of service region is different?

Table 20: ANOVA test to answer the seventeenth study question:

\begin{tabular}{|c|c|c|c|c|c|c|}
\hline \multicolumn{2}{|c|}{} & Total squares & Free degree & Squares average & F & Level of significant \\
\hline \multirow{2}{*}{} & $\begin{array}{c}\text { Between the } \\
\text { group }\end{array}$ & 0.529 & 5 & 0.106 & 0.939 & 0.458 \\
\cline { 2 - 6 } & $\begin{array}{c}\text { In the group } \\
\end{array}$ & 15.07 & 134 & 0.113 & & \\
\cline { 2 - 6 } & Total & 15.60 & 139 & & & \\
\hline
\end{tabular}

Because the test of variance analyzing is meaningless then we can that region of service don't have any effect on individual spirituality, in other word the individual spirituality between the personnel of different region aren't different.

Question 18- If the personnel's organizational spirituality Considering the service's region is different?

Table 21: ANOVA test to answer the eighteenth study question:

\begin{tabular}{|c|c|c|c|c|c|c|}
\hline \multicolumn{2}{|c|}{} & Total squares & Free degree & Squares average & F & Level of significant \\
\hline \multirow{2}{*}{$\begin{array}{c}\text { Between the } \\
\text { group }\end{array}$} & 2.33 & 5 & 0.467 & 3.94 & 0.002 \\
\cline { 2 - 5 } & In the group & 15.88 & 134 & 0.119 & & \\
\cline { 2 - 5 } & total & 18.21 & 139 & & & \\
\hline
\end{tabular}


Because the test of variance analyzing is significant at \% level we can conclude that service's region don't have any effect on organizational spirituality or in other words the organizational spirituality of the personnel at different regions are different.

Table 22 : Analogical test to answer the eighteenth question:

\begin{tabular}{|l|c|c|c|}
\hline \multirow{2}{*}{ Service's region } & number & \multicolumn{2}{c|}{ Level of confidence 95\% } \\
\cline { 3 - 4 } & & b & a \\
\hline ASAR & 20 & 2.96 & \\
\hline KHRRAM- ABAD & 5 & 3.01 & 3.12 \\
\hline BABA-HOSSIEN BRIDGE & 16 & 3.12 & 3.18 \\
\hline LORESTAN & 67 & 3.18 & 3.29 \\
\hline TANGE-FANNI & 21 & 3.29 & 3.47 \\
\hline AFARINNEH & 11 & & \\
\hline
\end{tabular}

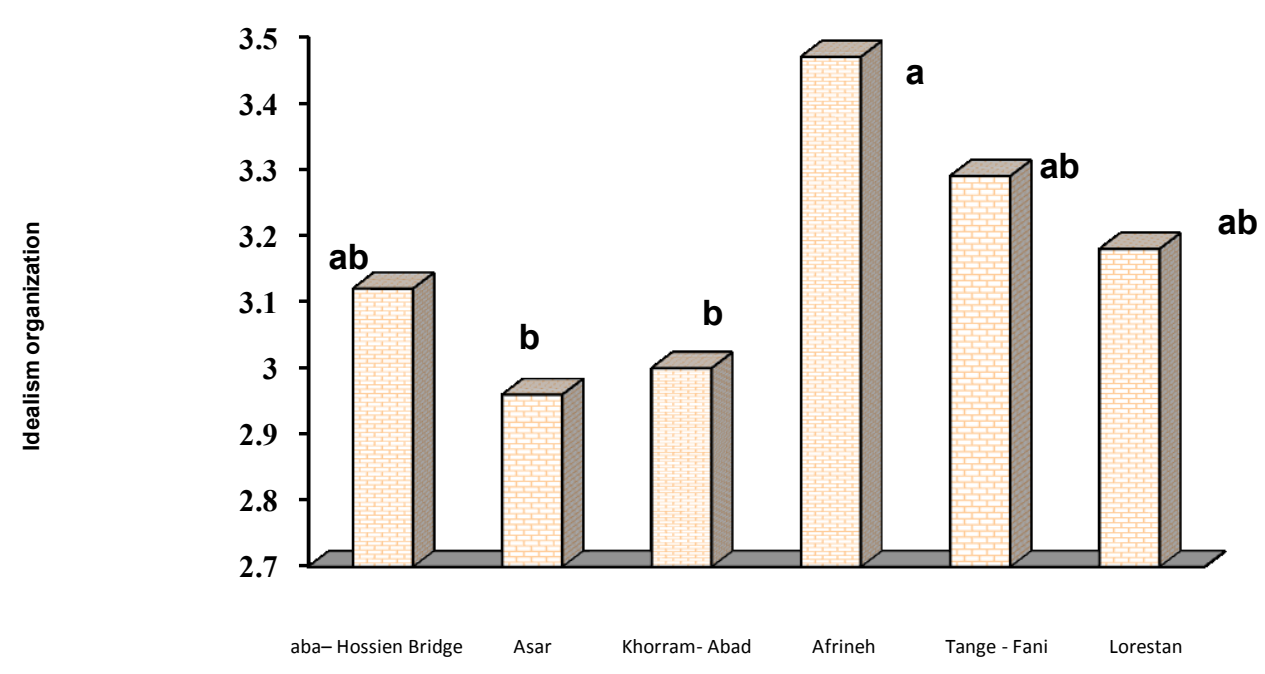

Graph 1 : Analogical test to answer the eighteenth question:

From this table and graph we can see that the highest organizational spirituality is at Afrinneh region.

\section{Study hypothesizes:}

1 -The first secondary hypothesizes: There are a relation between individual spirituality and pipe and telecommunication company of Lorestan region's job satisfaction's personnel.

Ho :There aren't any significant relation between individual spirituality and job satisfaction of the personnel of pipe and telecommunication company of Lorestan region.

$H_{1}$ :There are a significant relation between individual spirituality and job satisfaction of the personnel of pipe and telecommunication company of Lorestan region.

Table 23: Pierson Test to the first secondary hypothesis of the study:

\begin{tabular}{||c||c||c||}
\hline \hline Test value & number & Level of \\
\hline \hline 0.282 & 140 & 0.001 \\
\hline
\end{tabular}

From this table we can see that the Pierson Test is significant at the $1 \%$ level, then the Ho is rejected and $H_{1}$ will be accepted . then there are a relation between individual spirituality and personnel's job satisfaction of the pipe and telecommunication of Lorestan region.

The coefficient (\%282) show that although there are an non-significant relation between two variables, their relations are direct, namely the more personnel's individual spirituality will improved, the more their job satisfaction will be improved too.

2-The second secondly hypothesizes :There are a relation between organizational spirituality and pipe and job satisfaction of the personnel of the pipe and telecommunication of Lorestan region's. 
Ho :There isn't any significant relation between organizational spirituality and job satisfaction of the personnel of the pipe and telecommunication company of Lorestan region.

$H_{1}$ :There are a significant relation between organizational spirituality and job satisfaction of the personnel of the pipe and telecommunication company of Lorestan region.

Table 24: Pierson Test to the second secondary hypothesis of the study:

\begin{tabular}{||c||c||c||}
\hline \hline Test value & number & Level of significant \\
\hline \hline 0.251 & 140 & 0.003 \\
\hline \hline
\end{tabular}

From this table we can see that the Pierson Test at the $1 \%$ level, is significant the Ho is Ho is rejected and $H_{1}$ will be accepted . then there are a relation between organizational spirituality and job satisfaction of the personnel of the pipe and telecommunication company of the Lorestan region. The coefficient (\%251) show that although the relation between these two variable is non-significant, their relation is direct, namely the more personnel organizational spirituality will improved the more their job satisfaction will improved too.

3-The third secondly hypothesizes :There are a relation between organizational and individual spirituality of the personnel of the pipe and telecommunication company of the Lorestan region.

Ho :There isn't any significant relation between organizational spirituality and individual spirituality of the personnel of the pipe and telecommunication company of Lorestan region.

$H_{1}$ :There is a significant relation between organizational spirituality and and individual spirituality of the personnel of the pipe and telecommunication company of Lorestan region.

Table 25 : Pierson Test to the third secondary hypothesis:

\begin{tabular}{||c||c||c||}
\hline \hline Test value & number & Level of significant \\
\hline \hline 0.264 & 140 & 0.002 \\
\hline \hline
\end{tabular}

From this table we can see that the Pierson Test is significant at the level of $1 \%$, then Ho is rejected and $H_{1}$ is accepted . therefore there is relation between organizational and individual spirituality and of the personnel of the pipe and telecommunication company of the Lorestan region. The coefficient (\%264) show that although the relation is non-significant, their relation is direct and the more personnel's spirituality improve, the more organizational spirituality will improve.

\section{Conclusion:}

Undoubtedly fundamental changes is now form at the work environment, and spirituality is one of the main topics. There are many useful reasons to investigate the relation of spirituality and management .one of these reasons in the view of spirituality working. By spirituality working, many advantages will make to the organizational and personnel management . spirituality change the job nature . people search to find a meaning at their work , the search a way to connect their working life to their spirituality life and find a kind of aim and insight which is beyond the money . spirituality give a power to the people and this power cause they can connect to God at all of life aspects.As the work nature is changed, the relation of managers and personnel is changed too. At a period of time (the past) managers were like a commander and didn't any role at personnel's individual development.

Today managers are concluders who help their co - workers to find a meaning and aim . By spirituality manager will can not only improve the operation at the organization or work environment, but also they can be relax and satisfaction in which their friends and their co - workers to be happy and satisfied [3].

Changing the work nature has been caused changing at the organizational nature. Organizations gradually converted from small environment to economic and social activity to places to spirituality development. Organizations which provide opportunities to improve spirituality of the personnel will be more successful than the organizations which don't provide these opportunities.

Spirituality has a positive effect on the organizational operation. At the Organizations which attempt to improve the personnel's Spirituality, creativeness, satisfaction, team operation and organizational warranty is reported.

Personnel do export Organizations formed and designed which make easy their searching to meaning or development[12].

Considering the study's findings and the test results we can conclude spirituality at work environment is composed of meaning and aim of the work, honesty and sacrifice, philanthropy and life sanctification. considering the high Spirituality criterion of the Iranian personnel, we can by correct improving of this at the Organization get valuable interests such as job satisfaction. Informing these valuable factor and how to use them to improve the Organizational aims to the managers can also have a significant effect on improving 
Organization's operation. In addition to using Spirituality at group and individual level we can use this matter at different Organizational levels such as strategies, and policies, customer - oriented, personnel satisfaction and social responsibility. Then we propose that top managers pay attention more to know and support the spiritual dimensions.

\section{References}

[1]- Azar,A and Moumeni, M .(1998). Statics and its usage at management, SAMT publication, in Persian.

[2]- BahadoriNejad,M.(1984). Management base on spirituality, Tadbir Magazine, No 147, in Persian.

[3]- Scott, Richard.(1994). Organization as an intellectual system, natural and open system, translated by Hasan.Mirzai-Ahranjani and Flour Soltani, Tehran publication,in Persian.

[4]- Farhangi, A.A.(2008). Humanism relations, Rasa cultural services publication, in Persian .

[5]- Gibbons, P.(2000). Spirituality at work: Definitions, measures, assumptions, and validity claims, Paper Presented at the academy of management annual meetings, Toronto.

[6]- Hafeznia, M.R .(2003) An introduction of study method at humanism sciences, SAMT publication, in Persian.

[7] -John, Milkman. (2003). Workplace spirituality and employee work attitudes, ,Journal of Organizational Change Management, Vol 5, No 4.

[8]- Neal \& Lieberman.(2003). Introduction: the leading edge in research on spirituality and organizations, Journal of Organizational Change Management, Vol 6,No 3.

[9]- Kazemi, kh. (2004). Management base on spirituality, Tadbir Magazine,No 149, in Persian.

[10]- Kennedy,M.H.(2002). Spirituality in the Workplace: An Empirical Study of this Phenomenon ... DBA,Nova Southeastern University.

[11]- Mitroff and Denton.(1999). A Spiritual Audit of Corporate America: A Hard Look at Spirituality, Religion and Values in the Workplace.

[12]- Malekian, M .(2005). God and his environs topics, The centre of religion's studies, Qom, in persian.

[13]- Rastgar .Ali .(2005). Spirituality at the Organizational, doctoral thesis, Tehran University, in persian.

[14]- SeyyedJavadin,S.R \& Naserzadeh, S.M.R.(2006). Investigating the effect of personnel spirituality on their job satisfaction, the collection of essays of the third investigational management colloquium, Tehran, in persian.

[15] - Shafi-Abadi, A. (1996). Conducting and job consultation and choosing job 's theories, Roshd publication, in persian.

[16]- Shayegan, D.(2002). New conjuration ,Forty spies identity, Day Farzan publication, in persian.

[17]- Tajdari, P. (2005). Statistical methods in simple language, ATA publications, in persian.

[18]- Ursula, K.(1997). Spirituality in New Handbook of Living Religions, Oxford: Blackwell.

[19]- Wax, S. (2005). Spirituality at Work, Jeff Solomon, Series Editor. 